\section{今 \\ Francisco López Capillas Missa en Re Sol-Missa Aufer a nobis. Motetes}

\author{
CD en conmemoración del IV centenario del nacimiento \\ del compositor, Capella Prolationum Ensemble \\ La Danserye (Sevilla: Lindoro/Festival de Música Antigua \\ de Úbeda y Baeza, 20r4) \\ por \\ JAZMÍN RINCÓN** \\ Y JUAN MANUEL LARA CÁRDENAS***
}

Francisco López Capillas (I614-1674) fue un compositor novohispano que utilizó en sus obras, como pocos en la América de su época, elementos provenientes de la tradición polifónica renacentista del occidente europeo. Así, en sus composiciones se puede apreciar el hábil manejo del contrapunto imitativo, la aplicación de la parodia y la paráfrasis, el uso del lenguaje retórico característico de la época, la policoralidad y el uso tradicional de los enigmas. Este último recurso intelectual, tan poco empleado en la polifonía del Nuevo Mundo, llevó a los primeros investigadores de los archivos catedralicios en México - tales como Thomas E. Stanford, Lincoln

* Texto recibido el 3I de julio de 20I5; aceptado el 20 de agosto de 2015 .

** Becaria del doctorado en Historia del Arte.

*** Investigador titular del Centro Nacional de Investigación, Documentación e Información Musical "Carlos Chávez" (Cenidim), del INBA. Entre otros trabajos ha editado la obra completa de Hernando Franco (I532-1585) y Francisco López Capillas.
B. Spiess y más tarde Robert M. Stevensona llamar a Francisco López Capillas el "Ockehem de México", título que aún hoy se le asigna y con el cual habría de tenerse más cuidado, pues se corre el riesgo, como ya ha pasado con anterioridad con otros compositores novohispanos, de resituar su música a partir de una lógica dominante que no corresponde por completo a su obra y a su contexto cultural.

Aunque estamos frente al primer gran compositor americano reconocido como tal, paradójicamente su obra ha sido en gran parte ignorada, tanto en los estudios musicológicos, como en el ámbito de la ejecución. Por lo mismo, la presente grabación monográfica, creada en España en 2014 por el conjunto vocal-instrumental Capella Prolationum y el Ensemble La Danserye de instrumentos de viento, es el primer trabajo serio en el estudio e interpretación de la obra de Francisco López, lo cual merece nuestra atención y difusión.

Grabado con motivo de la celebración de los 400 ańos de su nacimiento, el disco contiene dos de las ocho misas que compuso Francisco López Capillas: la misa Re Sol, a 4 voces, basada en la canción homónima de Juan de Riscos (de la cual no hay seguridad de atribución a alguno de los varios Juan de Riscos de los que se tiene registro) y la misa Aufer a nobis, basada en el material temático de un motete propio. Los temas de la canción y el motete se utilizan en las cinco partes de las misas, procedimiento conocido como parodia y que el maestro utiliza en seis de sus ocho misas. Las piezas modelo van al inicio de cada una, además de que se intercalan algunos motetes. Aunque hubiese sido más apropiado que los motetes estuvieran después del Credo, que era el momento acostumbrado dentro de la celebración, el objeti- 
vo del disco, como bien lo menciona el musicólogo español Javier Marín López (también responsable de la investigación y editor del CD), no es reproducir el programa musical aplicable al rito de la misa, sino presentarnos un muestrario de la poco difundida obra de Francisco López Capillas. Para esto, el trabajo musicológico que Marín presenta en el libreto introductorio del disco da cuenta de la precisión y el detalle de sus observaciones sobre el trabajo compositivo de Francisco López Capillas, confrontado con los tratados y el contexto de la época, de los cuales Marín muestra ser un profundo conocedor.

Por otra parte, las notas hechas por Fernando Pérez Varela, del Ensemble La Danserye, dan cuenta asimismo de una búsqueda diligente en torno a lo que pudo ser la realidad sonora de las capillas catedralicias, en especial la de la Catedral de México, a partir de lo que informan sus actas de cabildo y otros documentos. Esto, poco común en la interpretación históricamente informada de la música hispanoamericana, además, se complementa con la experiencia práctica que tuvieron los integrantes del proyecto en la Catedral de Baeza (Jaén, 20I3), como parte del XVII Festival de Música Antigua de Úbeda y Baeza, la cual, entre otras cosas, ayudó a la toma de decisiones respecto a la combinación de voces e instrumentos en cada una de las obras del programa que se presenta en el CD. Así, las dos misas, el villancico final y el motete Cum iucunditate Nativitatem han sido interpretados en combinación de voces e instrumentos, mientras que los dos restantes motetes: Quicumque voluerit y Aufer a nobis, así como el responsorio Velum templi scissum, sólo instrumentalmente, es decir, sin voces y, por tanto, sin texto. Al respecto, cabe mencionar que la elaboración de la música vocal siempre dependía del significado del texto, lo que llevaba a compositores como Francisco López a usar elementos retóricos con el fin de traducir y reforzar las ideas expresadas por medio de las palabras. Esto último, sin embargo, se echa de menos en la interpretación de los motetes y del responsorio de la presente grabación. Por ejemplo, en el motete Cum iucunditate, compuesto para la fiesta de la natividad de la Virgen María sobre el tema de una antífona de las vísperas de la fiesta que se celebra el día 8 de septiembre, es especialmente importante dicha relación texto-música, pues el movimiento de las voces con las palabras en latín correspondientes tendría que dejar ver la alegría festiva que debía caracterizar una celebración como la del nacimiento de la Virgen María.

No obstante, uno de los aspectos más interesantes e innovadores de este proyecto fonográfico, tan propio del stile antico en el que Francisco López Capillas solía componer, es la propuesta de reconstruir una práctica hoy día perdida como lo es la lectura musical desde el facistol. La reconstrucción sonora que se ha hecho en una iglesia hispana como el Santuario de Nuestra Señora de Loreto en Espartinas (Sevilla), junto con la lectura directa de la notación mensural, tanto por parte de los cantantes (Capella Prolationum), como de los instrumentistas (Ensemble La Danserye), resulta prácticamente inédita en las grabaciones de música americana. Esto además saca a la luz, como las notas al disco lo explican en detalle, aspectos cruciales y de especial relevancia que modifican directamente la concepción de dicha música, a pesar de que estos últimos sean más evidentes en directo que mediante la grabación de audio. Por ejemplo, 
el hecho de estar todos los cantores y ministriles agrupados, prácticamente en contacto físico, permite una mejor sensación auditiva de las demás voces, a la vez que el sentido del compás implícito dentro de la propia capilla hace que la sonoridad tienda a ser muy compacta y rítmica, alcanzando niveles de volumen generalmente altos debido a la riqueza de armónicos, pero que el propio tejido polifónico se encarga de aliviar o densificar.

El presente proyecto destaca, así, que estamos hablando de música de facistol, es decir, música práctica hecha para acompañar las celebraciones de la liturgia de la Iglesia, lo que se suele olvidar cuando la lectura de las fuentes se traslada a la concepción contemporánea de lo que son las ediciones, las grabaciones y los conciertos.

La grabación de la Capella Prolationum y el Ensemble La Danserye, no sólo toma en cuenta todas estas cuestiones mediante un trabajo interdisciplinario de intérpretes e investigadores, sino que, además, inaugura un nuevo camino de experiencias interpretativas que redundará en un mejor y muy necesario entendimiento de lo que es la obra de un compositor mexicano de la talla de Francisco López Capillas. 